\title{
Examination of printability parameters of IPA free offset printing
}

\section{ABSTRACT}

Fountain solution system in offset printing system has significant impacts on the printing quality and fountain is the indispensable part of this system. The most important chemical added into the fountain solution is isopropyl alcohol. Fundamental features of isopropyl alcohol are reducing surface tension and adjusting and stabilizing $\mathrm{pH}$. However, in the course of time, the disadvantages of using alcohol have emerged. In the present study, the quality levels of IPA-based and IPA-free offset prints were compared. Specially designed test scale printing was carried out after IPA-based and IPA-free fountain solutions were prepared with the same ink on matt-coated paper under optimal printing conditions. Densitometric and spectrophotometric measurements were carried out on the prints and it was ensured that they were printed in accordance with ISO-12647-2:2013 offset printing standards. Special test scales that were printed were read through scale readers and colour profiles were obtained. Comparisons were carried out on the obtained IPA-free and IPAbased printing colour gamut. Microscopic images of the smallest dots were taken and edge sharpening was examined. Print brightness measurements were carried out for the selected areas on the test scale. The study practically demonstrated that printing performed by using IPA-free fountain solution produced a better and wider colour gamut, edge sharpening was better in the IPA-free systems as the number of prints increased and the prints made by using IPA-free fountain solution were brighter.

\section{Arif Ozcan}

Marmara University, School of Applied Sciences, Department of Printing Technologies, Istanbul, Turkey

Corresponding author:

Arif Ozcan

e-mail:

arifozcan@marmara.edu.tr

First recieved: 11.03.2017. Accepted: 05.06.2017.

\section{KEY WORDS}

CIE Lab, Colour Gamut, IPA-Free Printing, Offset Printing, Printing

\section{Introduction}

The development of technology is continuing and changing our understanding of quality together with new machines, tools and materials. Manufacturers are developing new products accordingly (Harrey et al. 2002; Pudas, Hagberg \& Leppavuori, 2002; Zjakić, Bates \& Milković, 2011; ). Offset printing is one of the most common printing systems. We can define offset printing as a chemical process possessing numerous parameters affecting the production process and print quality (Van,
2001). In printing, fountain solution is used in order to distinguish image areas and non-image areas (Kipphan, 2001; Oros, 2012; Rossitza, 2015) and this solution contains certain chemicals (Gómez, Quintana \& Villar, 2014). These chemicals are added into the fountain solution so as to reduce surface tension. Thanks to these chemicals, image areas and non-image areas display different surface characteristics (Järn et al., 2006; Gómez, Quintana \& Villar, 2014; ). For the functioning of the offset printing system; printing plate, blanket cylinder, printing ink and fountain solution are needed (Fuchs, 1996; Kiurski \& 
Oros, 2012). The fountain solution has certain key functions in the system (Fröberg et al., 2000). Although it may appear to be highly complicated at the beginning, this process can become considerably simple especially with the fountain solution being taken under control. In order to be able to control the print quality in offset printing, understanding the relations among ink, paper and fountain solution is of great importance (Tåg et al., 2009). In the simplest term, the offset printing system is based on a working principle where printing is performed only after water-receptive and ink-receptive areas are formed on the plate (Deshpande, 2011; Ozcan, 2011). In fact, the use of water during printing affects the print quality in a negative manner. However, fountain solution is an indispensable substance for the printing process and its use is a must (MacPhee, 1979; Tutak, 2014). Therefore, ink-water balance should remain stable during printing for a high quality print. Not only the ink but also the fountain solution should be taken under control to this end (Cox, 1992; Smyth, 2003; Liqiang, 2011). Even though ink and water are immiscible, a small amount of water mixes with the ink during printing. A fountain solution perfectly working with the offset ink should be used so as to precisely distinguish the printed-areas and non-printed areas on the plate (Demirel, 2011). In general, we can explain the functions of the fountain solution as wetting the plate adequately by using as less water as possible, protecting the plate surface, preventing the non-print areas on the plate from receiving ink and preserving its physical features when it mixes with the ink (Opusunju, 1981; Hattori \& Watanabe, 2008; Liu \& Shen, 2008).

\section{Use of Alcohol in the Fountain Solution}

The most important task of alcohol is to make the water more fluid by lowering the viscosity of the liquid. In offset printing, it is not possible to obtain quality printing without adding any additional additive into the water. Whether it is in IPA-based or IPA-free printing systems, it is possible to reach and maintain quality prints by adding a number of chemicals to the fountain solution.

Studies conducted on the fountain solution so far have generally aimed at achieving a better wetting capability for the printing plate through the addition of certain chemicals into the water. Alcohol has been used in the fountain solutions for a long time now. While the ratio of the alcohol used in the solutions was $15 \%$ at the beginning, this ratio fell to the level of 3-5\% in the course of time and now attempts are made for totally alcohol-free printing works. Mainly isopropyl alcohol (IPA) is used in the fountain solutions since it is more cost effective and easily accessible when compared to its alternatives. Although other cheaper alcohol components like methyl alcohol are available, they are not deemed suitable for use in offset printing in any parts of the world due to theirs hazards to health. Sensitivity towards environment issues has globally increased in recent years. Studies are being conducted in order to reduce or eliminate $\mathrm{CO}_{2}$ and VOCs components throughout the world. Since IPA contains volatile organic compounds (VOC) in its organic chemical structure, it has been accepted to be detrimental to human health and environment and certain restrictions have been imposed on its use (Dejidas, 1999). The amount of IPA added into the fountain solution has been considerably restricted in many places in the USA and new offset printing machines have been designed to be suitable for using IPA-free fountain solutions. In the EU countries as well, it is stipulated that the amount of alcohol added into the fountain solution should be below 5\%. In the USA, Occupational Safety \& Health Administration (OSHA) determined the maximum alcohol amount that the workers in the printing houses are allowed to inhale during the working hours (400ppm) and this was accepted as the legal limit. We can summarize the generally known characteristics of the IPA used in the fountain solution as such; IPA reduces the surface area of the fountain solution, spreads rapidly to the non-image areas and wets a larger area with a smaller amount of water. As it is known, surface tension of the water is $73 \mathrm{mN} / \mathrm{m}$ while surface tension of IPA is 22 mN/m (Lide, 2004; Gerilakan, 2011). On the other hand, surface tension of a traditional fountain solution or that containing $8 \%$ IPA is $40 \mathrm{mN} / \mathrm{m}$ (Özakhun, Zelzele \& Özcan, 2012). Surface tension of the IPA-free fountain solution used in the experimental studies is $32 \mathrm{mN} / \mathrm{m}$. The most important factor for alcohol-free printing is the correct use of chemicals. The fountain solution additives play a key role in obtaining reliable prints. The cleaning and maintenance of the dampening rollers should be done very well and the cleaning chemicals used shouldn't cause any damage on the dampening rollers.

IPA increases the viscosity of the fountain solution. Water becomes more fluid and this enables the water to reach the plate over the rollers in a shorter time. IPA evaporates more rapidly since it contains volatile compounds. However, this evaporation has scarcely any impact on the final drying of the print. IPA has a high toxicity level. This limit is easily reached in the pressroom environment. IPA disinfects the fountain solution. It prevents the formation of moulds, fungus and algae in the fountain solution. Actually fountain solutions containing alcohol contains such preventive chemicals as well. IPA does not prevent such formations on its own. IPA reduces conductivity. Since IPA constantly reduces conductivity, it can mislead the machine and printing master. The use of IPA is costly due to constant renewal especially in cases where additives are too many. In general, $40 \%$ of the alcohol used in the pressroom directly evaporates and mixes with the air. This means that $40 \%$ alcohol is wasted. IPA is combustive. Its flashpoint is $12^{\circ} \mathrm{C}$ and this means that special attention should be paid to appropriate usage and storage conditions (Deshpande, 2011). 
not adequate to characterize the water on its own and it

$\mathrm{pH}$ is the number defining the acid ions within the aqueous solution (Lawn \& Prichard, 2003). In sheet-fed offset printing, working at about 4,8-5,3 pH is preferred in general. This prevents delays that may result from possible drying due to the acidic content within the ink. Starting with a low pH tends to compensate the impacts of contamination originating from paper, ink, plate cleaners etc. Acting like a detergent, it prevents ink and oil-based contamination. Besides, proper chemical cleaning of the non-image areas is ensured. $\mathrm{pH}$ is an important criterion for the plate performance. This mild acidic solution does not cause any damage to the plate but if $\mathrm{pH}$ falls below 3.5, the plate can start rub off. Depending on the severity of the rubbing off, plate can become sensitive to ink, in other words, non-image areas may take ink. On condition that $\mathrm{pH}$ rises $(\geq 6)$, sensitivity in the plate can decrease. In other words, ink receptive areas can take water while water receptive areas can take ink. Keeping $\mathrm{pH}$ at the recommended range is of critical importance for the functioning of the system.

Today fountain solutions are buffered and major changes in $\mathrm{pH}$ are averted. Buffered solutions protect $\mathrm{pH}$ against changing alkalinity in the water, \% dosage and changes resulting from contaminants. Buffered solutions always tend to stabilize $\mathrm{pH}$ in the solution against ever-changing conditions. In this way, slight changes in the amount of the fountain solution used do not lead to radical changes in $\mathrm{pH}$ and the pressroom worker could control $\mathrm{pH}$ with less attention.

In the IPA-free printing products alternative to IPAbased ones, solutions working at lower $\mathrm{pH}$ values were produced. The reason why they were produced was to make their cleaning or disinfecting features stronger. These chemicals have lower $\mathrm{pH}$ values but this does not mean that they are more harmful or irritant. The main reason why these solutions have different $\mathrm{pH}$ values is that they have different acidic contents.

\section{Conductivity}

Conductivity is one of the most important concepts in offset printing and it should be understood its importance among the industry workers. The fact that a fountain solution works properly at the conductivity level of $1500 \mu \mathrm{S}$ does not necessarily mean that the fountain solution of another brand does not work at $2500 \mu \mathrm{S}$.

Conductivity is the competency of the aqueous solution to conduct the electricity. Particles called as electrically charged ions can carry an electric current. These ions mainly come from acids and salts in the solution source. When a higher amount of fountain solution is added into the fountain solution, the number of ions increase and this causes conductivity. Conductivity is also does not have direct impacts on the print quality.

Conductivity level should be consistent and reliable in the printing machine. Since IPA evaporates, it should be replenished but the ratio in the fountain solution may vary during replenishment. The more IPA is added, the more the conductivity reduces.

Alcohol free substances that are currently used instead of IPA affect conductivity strongly. With the water replenishment, a slight decrease can be seen in the conductivity level. In the alcohol free fountain solutions, conductivity is higher but more consistent compared to the alcohol-based systems. Higher conductivity should not cause panic. It means longer plate life and longer water tank life.

Fountain solution contains good water-soluble mineral salts as well as a high number of chemical compounds that can conduct electricity currents. As is the case with $\mathrm{pH}$ level, conductivity level of the fountain solution should be kept under control (Özakhun, Zelzele \& Ozcan, 2012). Any kind of contamination, either dirt on the paper or emulsified ink or other foreign matters, will affect conductivity and thus, following conductivity is a significant way of understanding whether the fountain solution is contaminated. However, conductivity may change depending on the water level and type of solution and it may be necessary to redetermine the conductivity level for the new conditions. Big deviations in the conductivity level indicate problems in the fountain solution. In this case, the most urgent option is to empty the water tanks. However, this can be a temporary precaution. Probable causes of the deviations in the conductivity level are as follows:

- There may be changes in $\mathrm{pH}$, hardness and conductivity of the new solution;

- Water circulation and feeding pumps should be controlled;

- If extra additives were used, ratios should be controlled;

- Plate and roller cleaners should be controlled;

- Are there any other contaminants entering into the fountain solution system, if yes, how and when?

Considering the above-mentioned probable causes, the problem must be solved immediately. Conductivity gives information only about what the water contains, it does not provide any information indicating what it is or whether it will be somehow useful for offset printing.

\section{Hardness}

Hardness refers to the dissolved metal ions within the water. They are generally calcium and magnesium salts. Water is described as "soft" if the ratio of dis- 
solved calcium and magnesium salts within it is low while it is described as "hard" in the exact opposite situation (Boysan \& Şengörür, 2009; Johnstone, 2003). This value varies depending on the geographical conditions of the region that the water is supplied from. Hardness degrees of waters are given in the Table 1.

\section{Table 1}

Water hardness table

\begin{tabular}{l|l|l|l|l}
\hline $\mathrm{Mg} \mathrm{Ca} / \mathrm{I}$ & $\begin{array}{l}\mathrm{Mg} \\
\mathrm{CaCO}_{3} / \mathrm{I}\end{array}$ & $\begin{array}{l}\text { French } \\
\text { Degrees }\end{array}$ & $\begin{array}{l}\text { German } \\
\text { Degrees }\end{array}$ & Hardness \\
\hline$<30$ & $<75$ & $<7.5$ & $<4.2$ & Very Soft \\
\hline $30-50$ & $75-125$ & $7.5-12.5$ & $4-7$ & Soft \\
\hline $50-100$ & $125-250$ & $12.5-25$ & $7-14$ & Mod. Hard \\
\hline $100-150$ & $250-375$ & $25-37.5$ & $14-21$ & Hard \\
\hline$>150$ & $>375$ & $>37.5$ & $>21$ & Very Hard \\
\hline
\end{tabular}

This is the first parameter that should be controlled since water constitutes almost $90 \%$ of the fountain solution. Changes in the water quality will directly affect the quality of the offset printing. The most important characteristic of water is its hardness.

Water hardness should range between $8^{\circ} \mathrm{dH}$ and $12^{\circ} \mathrm{dH}$ (German hardness) so that no problem is encountered during printing (Johnstone, 2003). Extremely hard waters contain abundant amounts of calcium salts and this leads to blockage in the pores of the rollers and reduction of the ink transfer through rollers. The accumulating calcium may block the fountain solution feeds and spraying systems and hinder their proper functioning. On the other hand, extremely soft waters lead to ink corrosion. Besides, soft water has a more corrosive impact than hard water. Therefore, it may lead to oxidation of the plate and corrosion of the metal components of the machine.

In order to prevent changes in the fountain solution, ion-changing process is applied for minimizing calcium and magnesium ions in the water. Tap water is filtered so that all magnesium, calcium, carbonate and bi-carbonate ions of the water are removed through demineralization. Only salt compounds not resulting in hardness or carbonate remain within the water. This process is the first step of preparing fountain solution. Afterwards, hardening agents can be added into water so as to adjust the total appropriate hardness degree. Generally, deionized or reverse osmosis is applied to desalinate the water.

\section{Surface Tension}

The most critical two functions expected from the fountain solution are rapid wetting of the plate and formation of smooth and thin water film over the plate. These functions are carried out by means of certain chemicals, which are isopropyl alcohol, and other chemicals replacing alcohol nowadays. Surfactants or surface-active agents are organic chemicals tending to concentrate on the surface due to their polar molecular structures. The amount of the surface-active agents within the fountain solution is of paramount importance. An excessive amount of surface-active agents may lead to ink emulsification (Dejidas, 1999).

\section{Experimental}

Komori Lithrone 28 (500mm-700mm) four colour, sheet-fed, offset printing machine was used in the study. Order of colour in printing was black, cyan, magenta and yellow and drying unit was not used. In the study, a test scale was prepared for printing in the $50 * 70 \mathrm{~cm}$ offset printing machine. This scale includes ECI2002CMYK i1_iO test scale for creating the colour gamut obtained in IPA-free and IPA-based printing; ISO 300 standard pictures for visual controls; dot gains of 1-100\% for examining dot forms; grey balance areas; trapping areas and CMYK colour bars for densitometric and spectrophotometric measurements (Figure 1).

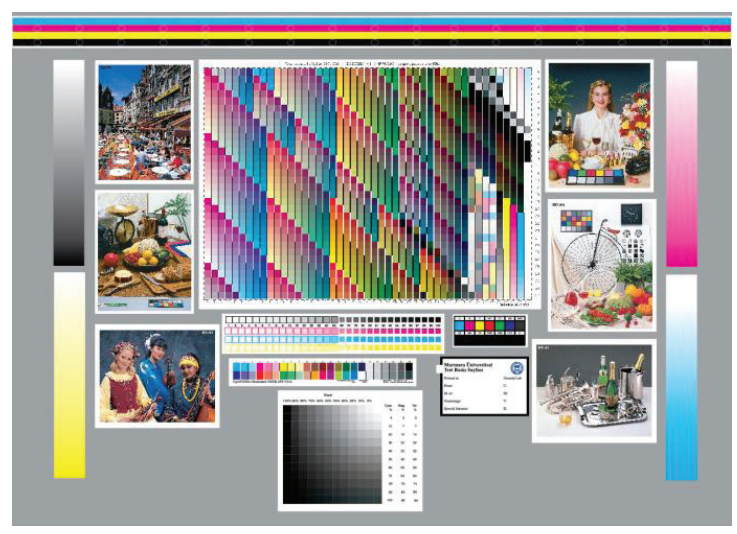

» Figure 1: $50 * 70 \mathrm{~cm}$ test scale print image

Plates were prepared with the CtP plate preparation method under equal conditions and prints were made on $300 \mathrm{~g} / \mathrm{m}^{2}$ matt-coated paper (Table 2) by using Sun Chemical SunLit Exact PSO sheetfed offset inks. In the printing machine, suitable for IPA-free printing, optimum surface properties and suitable for chemical structure, dampening rollers with high wettability and blanket with superior hydrophilic surface properties were used.

Prior to printing, general daily maintenance of the machine was carried out. The print speed was set at 15,000 sheets / hour and 300,000 prints were made. The printing machine was first prepared for IPA-free printing and IPA-free printing was performed. Ideal pH and conductivity values for the fountain solution were measured and recorded (Table 3). Paper and ink are prone to spoil the fountain solution because of alkali content. Therefore, the parameters of the fountain solution are constantly monitored and controlled. Chemicals such as anti-corrosion, $\mathrm{pH}$ regulator, hardness adjuster, 
cleaning and sedimentation inhibitor have been added in quantities determined for the fountain solution. There is not any study conducted on corrosion effects of fountain solutions used in the study. IPA-based and IPA-free fountain solutions used in the study were formulated as shown in Table 4. Fountain solution used in the study is re-osmosed and its total value of hardness is set to $10 \mathrm{dH}$ (water involving $100 \mathrm{ml} \mathrm{CaO}$ equivalent $\mathrm{CaCO}_{3}$ ) by adding re-hardener $\left(\mathrm{CaHCO}_{3}\right)$ afterwards. Water's total value of hardness is measured periodically and ensured to stay stable. It is constantly checked since it is known that conductivity value results from similar ions and it is ensured to stay at the values in Table 3. Furthermore, whether there is a clear difference between setting periods of IPA-based and IPA-free prints at the beginning of printing.

\section{Table 2}

Technical properties of matt coated paper

\begin{tabular}{l|l|l|l|}
\hline GSM & $\mathrm{g} / \mathbf{m}^{2}$ & $300 \mathrm{~g} / \mathbf{m}^{2}$ & ISO536 \\
\hline Brightness & $\%\left(\mathrm{D} 65 / 10^{\circ}\right)$ & 100 & ISO2470 \\
\hline Roughness & $\mu \mathrm{m}$ & 1.6 & ISO8979-4 \\
\hline Opacity & $\%$ & 98 & ISO2471 \\
\hline
\end{tabular}

\section{Table 3}

$\mathrm{pH}$ and conductivity levels of IPA-based and IPA-free fountain solutions prepared for the test print

\begin{tabular}{l|l|l}
\hline & pH & Conductivity $\mu$ S \\
\hline IPA-free fountain solution & $4.0-4.2$ & $1800-3000$ \\
\hline IPA-based fountain solution & $4.8-5.3$ & $800-1200$ \\
\hline
\end{tabular}

\section{Table 4}

Mixture ratios of the IPA-based and IPA-free fountain solutions prepared for the test print

\begin{tabular}{l|l|l|l}
\hline & Water & Solution & IPA \\
\hline IPA-free & $96 \%$ & $\begin{array}{l}4 \% \text { (buffer, anti-corrosion, pH } \\
\text { regulator, hardness adjuster, } \\
\text { cleaning and sedimentation } \\
\text { inhibitor - for without IPA) }\end{array}$ & $0 \%$ \\
\hline IPA-based & $87.5 \%$ & $\begin{array}{l}2.5 \% \text { (buffer, anti-corrosion, pH } \\
\text { regulator, hardness adjuster, } \\
\text { cleaning and sedimentation } \\
\text { inhibitor - for with IPA) }\end{array}$ & $10 \%$ \\
\hline
\end{tabular}

No special adjustment was made on the printing machine except for the general settings. After the printing started, densitometric and spectrophotometric measurements were carried out continuously over the scale via X-Rite eXact Handheld Spectrophotometer and the necessary ink adjustments were made meticulously so that the prints could be compatible with the CIELab values specified in ISO12647-2: 2013 (International Organization for Standardization, 2013) offset printing standard. Ink settings of the machine were recorded after optimal prints were obtained. After an adequate number of IPA-free print samples were obtained for the measure- ments, the fountain solution system of the machine was replaced by the IPA-added fountain solution. Measurements for the IPA ratio were made and $\mathrm{pH}$ and conductivity values recommended for IPA-based systems were obtained. For stabilizing the machine, prints were made with the previously recorded ink settings after printing went on for a while. Following the accurate prints, by taking a sample at 10,000 prints continuous spectrophotometric and densitometric (Table 5) measurements were carried out via X-Rite eXact Handheld Spectrophotometer and two fountain solution were compered by calculating the differences $(\Delta E)$ according to ISO 12647-2:2013 (Table 6). Measurement condition for spectrophotometer is $\mathrm{MO}$ for $\mathrm{ClE} \mathrm{L}^{*} \mathrm{a}^{*} \mathrm{~b}^{*}$ and $\mathrm{M} 3$ for density, colour space CIE L*a*b*, colour difference CIE $\triangle E^{*} 1976$ according to ISO 13655, spectral range $400 \mathrm{~nm}$ to $700 \mathrm{~nm}$, illuminant D50, observer $2^{\circ}$, polarizer filter on and $0 / 45$ degree geometry. The magnitude of the overall colour variation is given by

$$
\Delta \mathrm{E}=\sqrt{\Delta \mathrm{L}^{2}+\Delta \mathrm{a}^{2}+\Delta \mathrm{b}^{2}}
$$

and it was calculated as the average value of five measurements carried out on the total area (Ciofini et al., 2016).

\section{Table 5}

Spectrophotometric and densitometric measurements of IPA-based and IPA-free print samples via Spectro Eye spectrophotometer

\begin{tabular}{|c|c|c|c|c|c|c|c|}
\hline & & \multicolumn{2}{|c|}{$\mathbf{L}$} & \multicolumn{2}{|c|}{ a } & \multicolumn{2}{|c|}{ b } \\
\hline & & Ave. & Std. & Ave & Std. & Ave & Std. \\
\hline \multirow{2}{*}{$\mathrm{C}$} & IPA-Free & 54.64 & 1.27 & -33.9 & 1.18 & -49.92 & 1.35 \\
\hline & IPA-Based & 56.84 & 1.45 & -34.1 & 1.32 & -48.66 & 1.60 \\
\hline \multirow{2}{*}{$\mathrm{M}$} & IPA-Free & 46.63 & 1.42 & 71 & 1.76 & -5 & 1.56 \\
\hline & IPA-Based & 48.53 & 1.47 & 70 & 1.82 & -8 & 1.65 \\
\hline \multirow{2}{*}{$\mathrm{Y}$} & IPA-Free & 88 & 1.30 & -5 & 1.12 & 90 & 1.23 \\
\hline & IPA-Based & 86 & 1.70 & -6 & 1.65 & 87 & 1.77 \\
\hline \multirow{4}{*}{$\mathrm{K}$} & IPA-Free & 18 & 1.27 & -0.2 & 1.24 & 1.3 & 1.66 \\
\hline & & 19 & 1.45 & -0.3 & 1.42 & 1.6 & 1.50 \\
\hline & & \multicolumn{2}{|c|}{ Solid Density } & \multirow{2}{*}{\multicolumn{2}{|c|}{\begin{tabular}{|l}
$40 \%$ \\
Tonal Value \\
Increase
\end{tabular}}} & \multirow{2}{*}{\multicolumn{2}{|c|}{$\begin{array}{l}80 \% \text { Tonal } \\
\text { Value } \\
\text { Increase }\end{array}$}} \\
\hline & & Ave. & Ave. & & & & \\
\hline \multirow{2}{*}{$\mathrm{C}$} & IPA-Free & 1.46 & 0.05 & \multicolumn{2}{|c|}{$52-40=12 \%$} & \multicolumn{2}{|c|}{$90-80=10 \%$} \\
\hline & IPA-Based & 1.47 & 0.04 & \multicolumn{2}{|c|}{$56-40=16 \%$} & \multicolumn{2}{|c|}{$92-80=12 \%$} \\
\hline \multirow{2}{*}{ M } & IPA-Free & 1.48 & 0.06 & \multicolumn{2}{|c|}{$52-40=12 \%$} & \multicolumn{2}{|c|}{$89-80=9 \%$} \\
\hline & IPA-Based & 1.40 & 0.05 & \multicolumn{2}{|c|}{$55-40=15 \%$} & \multicolumn{2}{|c|}{$91-80=11 \%$} \\
\hline \multirow{2}{*}{$\mathrm{Y}$} & IPA-Free & 1.05 & 0.06 & \multicolumn{2}{|c|}{$51-40=11 \%$} & \multicolumn{2}{|c|}{$87-80=7 \%$} \\
\hline & IPA-Based & 0.96 & 0.04 & \multicolumn{2}{|c|}{$54-40=14 \%$} & \multicolumn{2}{|c|}{$90-80=10 \%$} \\
\hline \multirow{2}{*}{$\mathrm{K}$} & IPA-Free & 1.95 & 0.07 & \multicolumn{2}{|c|}{$54-40=14 \%$} & \multicolumn{2}{|c|}{$90-80=10 \%$} \\
\hline & IPA-Based & 1.83 & 0.07 & \multicolumn{2}{|c|}{$57-40=17 \%$} & \multicolumn{2}{|c|}{$92-80=12 \%$} \\
\hline
\end{tabular}

In addition, IPA-free and IPA-based prints were compared with the dot area percentages measured by the microscope. For dot area \% measurements X-Rite vipFLEX RGB 640*480, 10.000 ppi sensor, 150 Ipi screen ruling microscope was used. 


\section{Table 6}

CIE Lab difference $(\Delta \mathrm{E})$ between two damping solution according to ISO $12647-2: 2013$

\begin{tabular}{|c|c|c|} 
& IPA-free & IPA-based \\
\hline $\mathrm{C}$ & 1.21 & 2 \\
\hline $\mathrm{M}$ & 1.74 & 2.34 \\
\hline $\mathrm{Y}$ & 1.98 & 3.46 \\
\hline $\mathrm{K}$ & 1.87 & 2.58 \\
\hline
\end{tabular}

\section{Results}

According to the results of the IPA-based and IPA-free printing performed under the ideal pressroom conditions, two-dimensional (xy) and two-dimensional (ab) colour gamuts obtained in the IPA-free prints made with the same ink settings are wider than that of the IPA-based printing (Figure 2 and Figure 3).

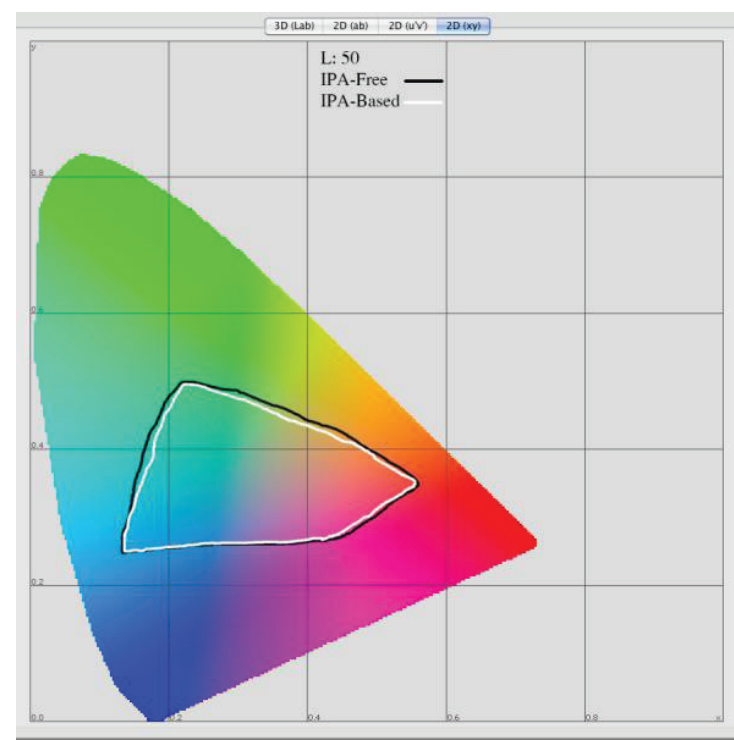

» Figure 2: Two-dimensional (xy) colour gamuts obtained from IPA-based and IPA-free prints

Densitometric measurements on the prints made by using the same ink settings demonstrate that cmyk density values are higher in the IPA-free printing (Table 5). The reason of this finding is that the surface tension of the fountain solution concentrate used in IPA-free printing is lower than that of the IPA-based fountain solution. Since a larger surface can be wetted by using a lesser amount of water in this case, brighter and saturated colours are obtained with a lesser amount of ink in IPA-free printing. Considering the capability of water and IPA-based fountain solution to dilute the ink and to reduce its colour intensity, the importance of performing printing with a trace of water is better understood. This also means that ink can be saved. It was observed that dot gain values of printings with use of IPA-based fountain solutions was more than IPA-free based foun- tain solutions the dot gain values measured from dots of $80 \%$ and $40 \%$ (Table 5). However, as seen in Figure 5 , losses in sharpness of edge and impairment take place especially after 200.000 prints. CIE Lab difference $(\triangle E)$ values of IPA-free prints are better than IPA-based printing according to ISO 12647-2:2013 (Table 6).

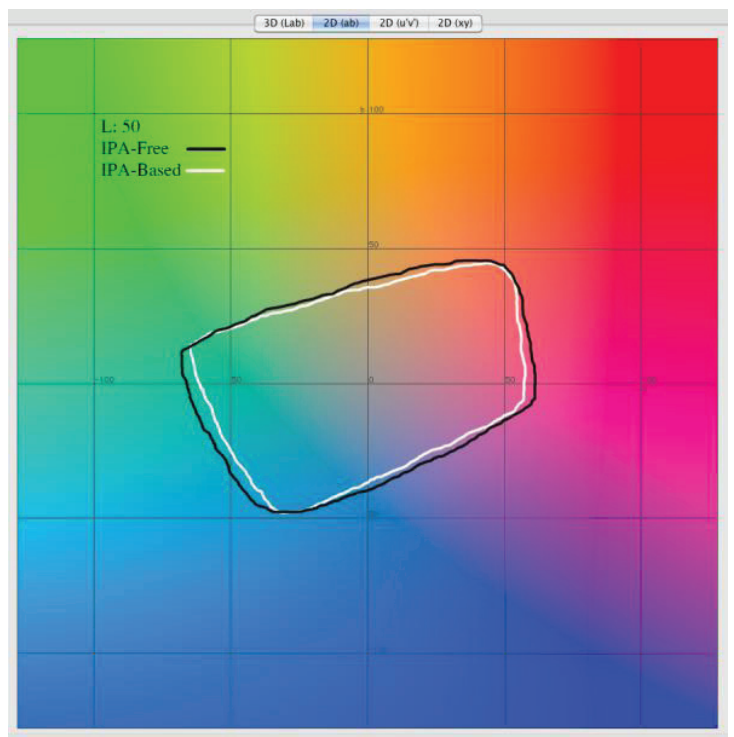

» Figure 3: Two-dimensional ( $a b)$ colour gamuts obtained from IPA-based and IPA-free prints
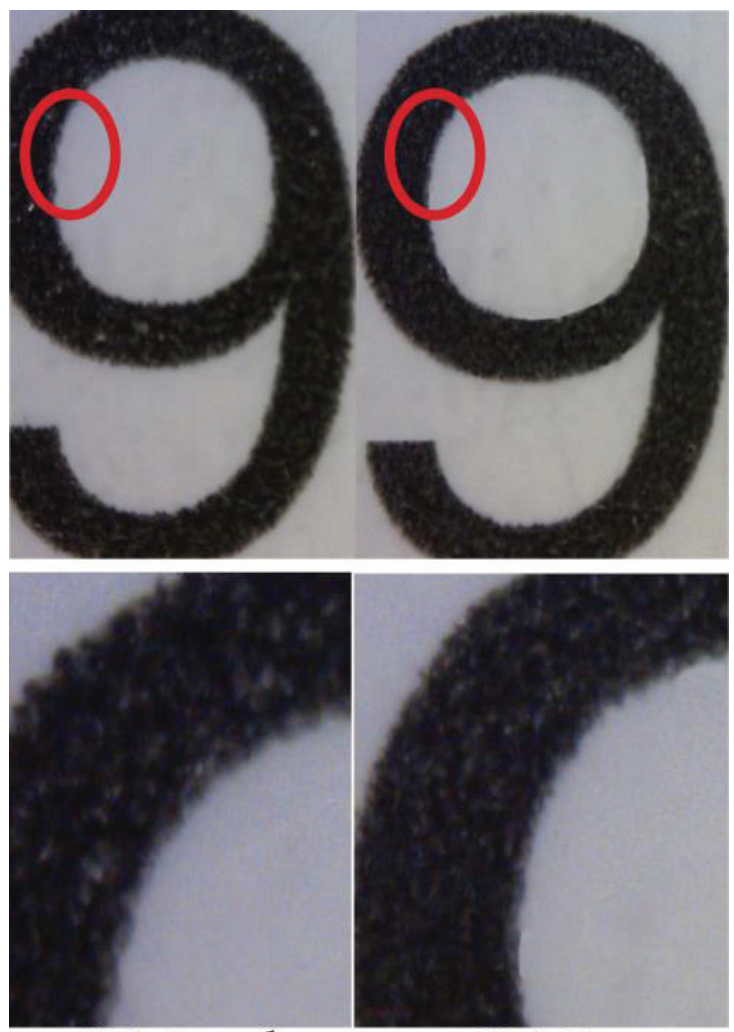

IPA-Based

IPA-Free

» Figure 4: IPA-based and IPA-free printing microscopic images taken from the texted areas on the test scale 

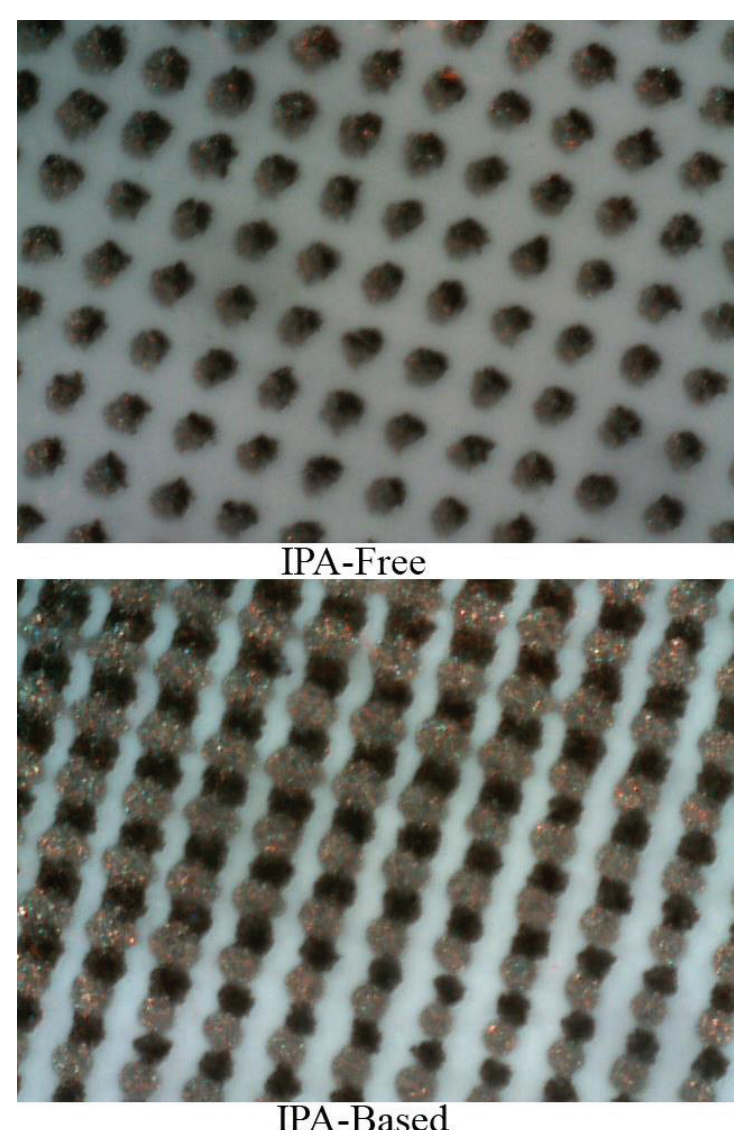

IPA-Based

» Figure 5: IPA-free and IPA-based printing microscopic images taken from the dot areas on the test scale

When it is observed whether there is a difference between preparation periods of IPA-based and IPA-free prints at the beginning of printing, it is confirmed that there is not much of a difference both in terms of preparation period and started paper wastes. The microscopic images taken from the texted areas on the print samples as well demonstrate that edge sharpenings of the IPAfree printing is better when compared to the IPA-based printing (Figure 4).

In the measurements made on the dot areas, it was seen that edge sharpening disappeared, shadows emerged and thus, dots were bigger or smaller than they should be and were not clear as the print work proceeded (200.000 prints) (Figure 5). Even in the dot area \% measurements carried out via a special microscope, the measurements on the specified areas of IPA-based and IPA-free prints showed that the deformation in the dot forms became evident following the $200.000^{\text {th }}$ print in IPA-based printing and therefore, accurate dot area $\%$ measurements could not be performed (Figure 6).

\section{Conclusions}

According to the two-dimensional colour gamuts acquired from prints performed with the same setting of ink, colour gamuts obtained from IPA-Free prints are wider than IPA-Based.
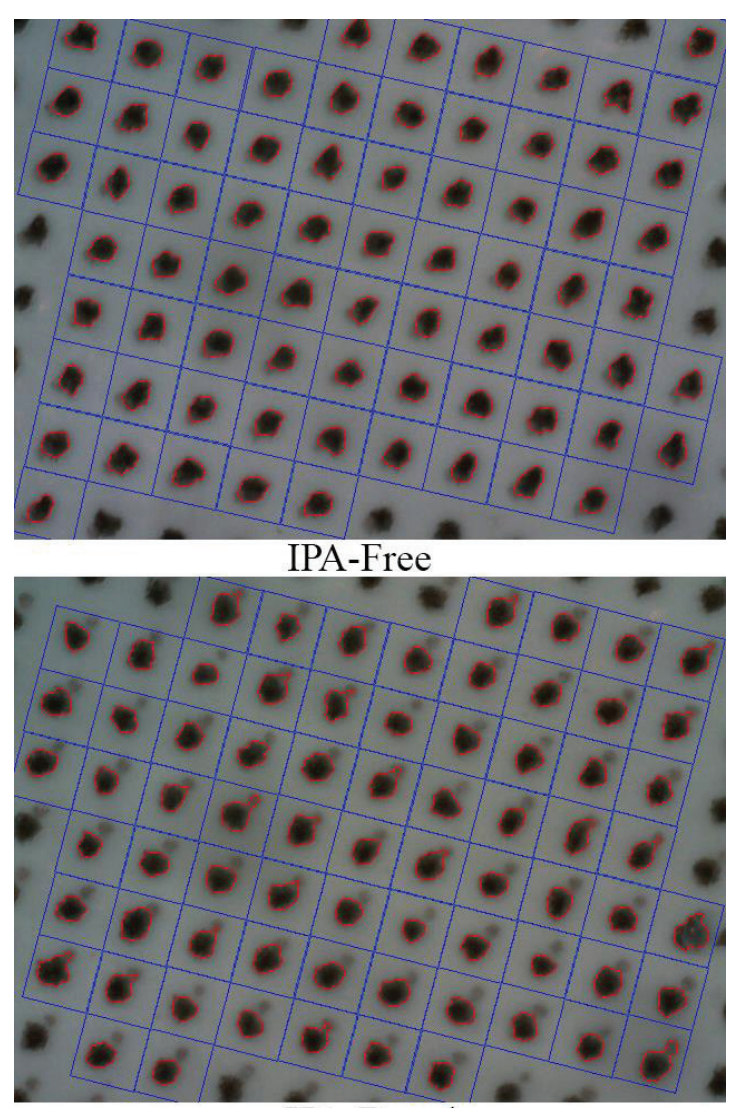

\section{IPA-Based}

» Figure 6: Image of dot area \% measurements made on the previously specified areas on the test scale

Solid densities of IPA-free prints are higher than the other one in densitometric measurements. However, considering dot swellings, dot swellings in IPA-based prints are measured higher than IPA-free prints. This situation actually is not the result of dot swelling. These are about losses in sharpness of edge and impairment of dots. Impairments in forms of dots are clearly seen in microscopic images especially after further prints (200.000 prints).

There is not an explicit difference between IPA-free and IPA-based prints in comparisons in terms of preparation periods and started paper wastes at the beginning of printing. It is observed that edge sharpness in IPA-Free prints is better when edge sharpness of dots is considered. It is measured in print gloss measurements that IPA-free prints have much higher print gloss values compared to IPA-based prints.

In addition to these factors, some other points should be taken into consideration as well for an accurate and reliable IPA-free printing. In brief, printing equipment and fountain solutions should primarily be examined and water should be analyzed. Accordingly, IPA-free printing products should be selected. A special attention should be paid to the cleaning of the water tanks and temperature values $\left(9-12^{\circ} \mathrm{C}\right)$. Hardness of the rollers should be considered; a hardness value of 25-32 shore A is recommended for the hardness of a water roller. These hardness values are of great importance for the transfer of an adequate amount of water to the plate by the fountain solution. 


\section{References}

Boysan, F. \& Şengörür, B. (2009) The importance of water hardness for human health. Sakarya University Journal of Science. 24 (1), 7-10. Available from: http://oaji.net/articles/2014/1084-1418118559. pdf [Accessed 20th June 2016].

Ciofini, D., Striova, J., Camaiti, M. \& Siano, S. (2016) Photo-oxidative kinetics of solvent and oil-based terpenoid varnishes. Polymer Degradation and Stability. 123, 47-61. Available from: doi: 10.1016/j.polymdegradstab.2015.11.002 [Accessed 26th May 2016].

Cox, D. E. (1992) Fountain solution pH and conductivity changes caused by paper extractables during offset printing. MSc thesis. Western Michigan University.

Dejidas, L. P. (1999) Alcohol-free printing. GatfWorld: SecondSight. 74, 23-37. Available from: http://pneac.org/sheets/litho/alcoholfreeprinting.pdf [Accessed: 14th June 2015].

Demirel, M. (2001) Fount solution concentrate components and effects. IV International Printing Technologies Symposium. 137-155.

Deshpande, S. S. (2011) Fountain solution in lithographic offset printing. Journal of Engineering Research and Studies. 2 (2), 82-88. Available from: http://www. technicaljournalsonline.com/jers/VOL II/JERS VOL ॥ ISSUE II APRIL JUNE 2011/ARTICLE 18 JERS VOL II ISSUE II APRIL- JUNE 2011.pdf [Accessed : 14th June 2016].

Fröberg, J. C., Voltaire, J., Sundin, M. \& Tiberg, F. (2000) Effect of ink-fountain balance on ink-tack development. In: Technical Association of the Pulp and Paper Industry. 2000 International Printing \& Graphic Arts: Proceedings of the 2000 TAPPI International Printing and Graphic Arts Conference, 1-4 October 2000, Savannah, USA. Norcross, TAPPI Press. pp. 133-138.

Fuchs, B. (ed.) (1996) The Influence of the quality of raw water in damping solutions on newspaper printing. IFRA. Report number: 1.15.

Gerilakan, A. (2011) Surface Tension in Liquid Inks and Factors Affecting the Surface Tension. Dyo Printing Inks.

Gómez, N., Quintana, E. \& Villar, J. C. (2014) Effect of paper surface properties on coated paper wettability with different fountain solutions. BioResources. 9 (3), 4226-4241. Available from: doi:10.15376/ biores.9.3.4226-4241 [Accessed 16th May 2016]

Harrey, P. M., Ramsey, B. J., Evans, P. S. A. \& Harrison, D. J. (2002) Capacitive-type humidity sensors fabricated using the offset lithographic printing process. Sensors and Actuators B: Chemical. 87 (2), 226-232. Available from: doi: 10.1016/S09254005(02)00240-X [Accessed 15th January 2017].

Hattori, H. \& Watanabe, K. (2008) Eco-friendly fountain solution for offset printing. Fujifilm Research \& Development. 53, 19-21. Available from: http://www. fujifilm.com/about/research/report/053/pdf/index/ ff_rd053_004_en.pdf [Accessed 26th May 2016].

International Organization for Standardization. (2013) ISO 12647-2:2013. Graphic Technology - Process
Control for the Production of Half-tone Colour Separations, Proof and Production Prints - Part 2: Offset Lithographic Processes. Geneva, International Organization for Standardization.

Järn M., Tåg, C. M., Jarnström, J., Granqvist, B. \& Rosenholm, J. B. (2006) Alternative models for determining the surface energy components in offset printing. Journal of Colloid and Interface Science. 301 (2), 668-676. Available from: doi: 10.1016/j. jcis.2006.05.018 [Accessed 16th May 2016].

Johnstone, W. P. (2003) The influence of water hardness on the performance of lithographic ink: Part I. Available from: http://www.lia.com.au/images/WaterHardness Part I and II.pdf [Accessed 14th June 2016].

Kipphan, H. (2001) Handbook of Print Media. New York, Springer.

Kiurski, J. \& Oros, I. (2012) The influence of pH/ conductivity of fountain solution on dot circularity, line and text raggedness, Journal of Graphic Engineering and Design. 3 (2), 1-7. Available from: www.grid.uns.ac.rs/jged/download. php?fid=125 [Accessed 16th May 2016].

Lawn, R. \& Prichard, F. E. (2003) Practical Laboratory Skills Training Guides: Measurement of $\mathrm{pH}$. London, RSC Publishing.

Lide, D. R. (2004) CRC Handbook of Chemistry and Physics. 85th ed. Cleveland, CRC Press.

Liu, F. \& Shen, W. (2008) Forced wetting and dewetting of liquids on solid surfaces and their roles in offset printing. Colloids and Surfaces $A$ : Physicochemical and Engineering Aspects. 316 (1-3), 62-69. Available from: doi: 10.1016/j.colsurfa.2007.08.037 [Accessed 21th May 2016].

MacPhee, J. (1979) An engineer's analysis of the lithographic printing process. Available from: https://www. printing.org/taga-abstracts/ an-engineers-analysis-of-the-lithographic-printing-process [Accessed 16th May 2016].

Opusunju, S.A. (1981) Concentration and conductivity of fountain solutions: A study of the relationship between concentration of materials/ electrochemical conductivity of fountain Solutions and offset lithographic plate performance. MSc thesis. Rochester Institute of Technology.

Oros, I. (2012) The influence of physico-chemical parameters of fountain solution on print quality. International Journal of Modern Engineering Research. 2 (5), 3585-3593. Available from: http://www.ijmer.com/papers/Vol2_Issue5/ CY2535853593.pdf [Accessed 15th May 2016].

Özakhun, Ş. C., Zelzele, Ö.B. \& Ozcan, A. (2012) Analysis of the fountain solution in the offset printing in terms of printability. Asian Journal of Chemistry. 24(2), 641-645.

Ozcan, A. (2011) Analyzing the effect of paper's porosity on trapping and colour value. Asian Journal of Chemistry. 23 (6), 2755-2758.

Pudas, M., Hagberg, J. \& Leppavuori, S. (2002) The absorption ink transfer mechanism of gravure offset printing for electronic circuitry. IEEE Trans- 
actions on Electronics Packaging Manufacturing. 25 (4), 335-343. Available from: doi:10.1109/ TEPM.2002.807728 [Accessed 15th January 2017].

Rossitza, S. (2015) Offset printing without isopropyl alcohol in damping solution. Energy Procedia. 74, 690-698. Available from: doi: 10.1016/j. egypro.2015.07.804 [Accessed 15th May 2016].

Smyth, S. (2003) The print and production manual. 9th ed. Leatherhead, Pira International.

Tåg, C.M., Pykönen, M., Rosenholm, J. B. \& Backfolk, K. (2009) Wettability of model fountain solutions: The influence on topo-chemical and-physical properties of offset paper. Journal of Colloid and Interface Science. 330 (2), 428-436. Available from: doi: 10.1016/j.jcis.2008.10.058 [Accessed 16th May 2016].

Tutak, D. (2014) Comparing The Color Gamuts of Different Paperboard Surfaces Used in Package Printing, AJIT-e: Online Academic Journal of Information Technology. 5 (17), 57-66. Available from: doi: 10.5824/1309-1581.2014.4.004.x [Accessed 17th May 2016].

Van Roy E. (2002) pH, Conductivity and Offset Printing. [Lecture] Western Wisconsin Technical College, 26th February.

Zjakić, I. Bates, I. \& Milković, M. (2011) A study of dot gain and gamut for prints made with highly pigmented inks. Technical Gazette. 18 (2), 227-235. Available from: http://hrcak.srce. $\mathrm{hr} / 69588$ [Accessed 15th January 2017].

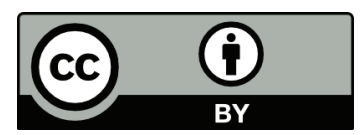

(C) 2017 Authors. Published by the University of Novi Sad, Faculty of Technical Sciences, Department of Graphic Engineering and Design. This article is an open access article distributed under the terms and conditions of the Creative Commons Attribution license 3.0 Serbia (http://creativecommons.org/licenses/by/3.0/rs/). 